\title{
Risk Prediction of Subsequent Early Stroke in Patients with Transient Ischemic Attacks
}

\author{
Anastasios Chatzikonstantinou Marc E. Wolf Anke Schaefer \\ Michael G. Hennerici \\ Department of Neurology, Universitätsmedizin Mannheim, University of Heidelberg, Mannheim, Germany
}

\section{Key Words}

Transient ischemic attack . Stroke recurrence .

Symptom fluctuations $\cdot A B C D 2$ score $\cdot A B C D 3-I$ score

\begin{abstract}
Background: Prognostic clinical scores (ABCD2 and ABCD3I), as well as specific clinical signs and symptoms (e.g. fluctuations) have been used to predict early stroke risk in patients admitted to hospital after transient ischemic attacks (TIAs). We compared the utility of these scores and signs for prognosis and outcome. Methods: 235 patients with TIAs admitted to our Comprehensive Stroke Center entered the study. Patients were monitored over 3 days with detailed brain imaging [diffusion-weighted imaging (DWI) was performed either directly on admission or within $24 \mathrm{~h}$ from admission and was repeated in cases of stroke recurrence], vascular ultrasound imaging, repeated neurological scoring and continuous ECG monitoring. Duration, fluctuation of symptoms, clinical patterns of initial signs and/or symptoms as well as general patient characteristics and stroke risk factors, including atrial fibrillation (AF), were analyzed and recorded in our stroke databank. Fluctuation of symptoms was defined as the complete remitting and relapsing of TIA symptoms for $\geq 2$ times in the acute phase within the first
\end{abstract}

$24 \mathrm{~h}$. This differs from the 'dual TIA' definition of the ABCD3I score, which is defined as 'an earlier TIA within 7 days of the index event'. $A B C D 2$ and $A B C D 3-I$ scores were calculated and the patients were placed into three categories: 'low', 'moderate' and 'high' risk for every score. Risk associations were assessed by the $x^{2}$ test and the $\varphi$-coefficient. Results: Out of 235 patients, 17 patients (7.2\%) experienced an early stroke during hospitalization (mean duration $7.4 \pm 2.7$ days). $A B C D 2$ scores failed to predict early stroke $(p=0.544)$. $A B C D 3-1$ scores correlated better with early stroke recurrences $(p=0.021)$. Positive DWI findings $(6 / 17 ; 35.3 \%)$, presence of carotid stenosis $(3 / 17 ; 17.6 \%)$ or $\mathrm{AF}(1 / 17 ; 5.9 \%)$ alone failed to predict early stroke. Fluctuations of symptoms, however, showed a significant prediction for early stroke after TIA: $13 / 17$ (76.5\%) patients $(p<0.001)$. The combination of symptom fluctuation and MR-DWI-positive findings (4/17; $23.5 \%$ ) also turned out to be statistically significant in this regard ( $p=0.003$ ), while the combination of symptom fluctuations with carotid stenosis $\geq 50 \%$ did not ( $p=0.151$ ). Combining fluctuations with carotid stenosis and DWI-positive findings did not improve the result $(p=0.029)$. Conclusions: While the ABCD3-I score is indeed very useful, symptom fluctuations seem to be the best available and an easily accessible and applicable parameter for individual prediction of a high early stroke risk after TIAs. Copyright $\odot 2013 \mathrm{~S}$. Karger AG, Basel

\section{KARGER}

E-Mail karger@karger.com www.karger.com/ced
(C) 2013 S. Karger AG, Basel

1015-9770/13/0362-0106\$38.00/0
Dr. Anastasios Chatzikonstantinou, MD

Department of Neurology, Universitätsmedizin Mannheim

Theodor-Kutzer-Ufer 1-3

DE-68167 Mannheim (Germany)

E-Mail chatziko@ neuro.ma.uni-heidelberg.de 


\section{Introduction}

Patients with transient ischemic attack (TIA) are known to be at high risk with regard to subsequent early stroke [1-4]. Since this risk was realized, different scores and strategies have been suggested for stroke prediction after TIA. Early neuroimaging detection of cerebral ischemia has been suggested to be a strong prognostic factor, as infarction on diffusion-weighted images (DWI) has been shown to be associated with high early stroke risk [5-7]. The ABCD2 score was developed for acute risk stratification [8]. The ABCD3-I score additionally takes into consideration positive DWI findings, dual TIA episodes and relevant carotid stenosis $[9,10]$. This combination has been claimed to be of particular value for individual stroke prediction. Previous studies have shown that 'unstable' TIAs, i.e. with symptom fluctuations, can identify patients at very high risk for subsequent stroke $[11,12]$. We thus compared the different risk assessment scores with clinical fluctuations in a TIA patient cohort and with regard to early stroke risk prediction.

\section{Methods}

235 TIA patients consecutively admitted to our Stroke Competence Center were recruited for this study. The diagnosis of TIA was based on the traditional time-oriented definition with neurological symptoms of supposed cerebrovascular origin lasting less than $24 \mathrm{~h}$. The standard operating procedure in our department requires all TIA patients to be admitted to the Stroke Unit. All patients underwent a thorough neurological examination and NIHSS scoring upon admission and every $6 \mathrm{~h}$ subsequently, according to the standards of Stroke Unit treatment. Prompt brain imaging was performed in all patients. Most patients $(229 ; 97.5 \%)$ received MRI including DWI sequences, unless contraindications were present. In addition, cerebrovascular extra- and transcranial Doppler/duplex examinations were performed in all patients. DWI was performed either directly on admission or within $24 \mathrm{~h}$ from admission and was repeated in cases of stroke recurrence. Carotid stenosis was defined according to the ECST criteria. Every patient was ECG monitored for at least $24-72 \mathrm{~h}$ while in our Stroke Unit. Duration, fluctuation of symptoms, clinical patterns of initial signs and/or symptoms as well as general patient characteristics and stroke risk factors, including atrial fibrillation (AF), were analyzed and recorded in our stroke databank. Fluctuation of symptoms was defined as the complete remitting and relapsing of TIA symptoms (i.e. aphasia, dysarthria, ataxia, motor and/or sensory deficits) for $\geq 2$ times in the acute phase within the first $24 \mathrm{~h}$. Only symptoms that completely remitted in between were considered as fluctuations for the purpose of this study. This differs from the 'dual TIA' definition of the ABCD3-I score, which is defined as 'an earlier TIA within 7 days of the index event'. All data were collected as a part of the investigation of the quality of care, in accordance with existing German law and regulations and with approval of the local ethics committee. No patients were exposed to additional interventions, questioning or examinations because of this study. Accordingly, ABCD2 and ABCD3-I scores were calculated and the patients were divided into three categories: 'low', 'moderate' and 'high' risk for every score, according to recently published proposals $[8-10]$.

\section{Statistical Analysis}

Risk associations were assessed by the $\chi^{2}$ test and the $\varphi$-coefficient. Statistical analysis was performed using the SPSS, version 17.0 (IBM, USA).

\section{Results}

The mean age of patients was 66.1 years $(\mathrm{SD}=13.9)$; $55.3 \%$ were male. Sixty-seven patients $(28.5 \%)$ presented with symptom fluctuations at onset. Twenty-one (8.9\%) patients exhibited AF and $36(15.3 \%)$ a significant carotid stenosis $\geq 50 \%$. In $50(21.3 \%)$ patients, MR-DWI showed signs of acute cerebral ischemia corresponding to clinical signs/symptoms.

Using the ABCD2 score, classification was as follows: 99 (42.1\%) patients with 'low', 114 (48.5\%) with 'moderate' and $22(9.4 \%)$ patients with 'high' risk. Using the ABCD3-I score, $74(31.5 \%)$ patients were classified as 'low', $152(64.7 \%)$ as 'moderate' and 9 (3.8\%) as 'high' risk.

Seventeen (7.2\%) patients suffered an early stroke during their hospitalization (mean duration: $7.4 \pm 2.7$ days). The ABCD2 score did not achieve a significant correlation with early stroke $(\mathrm{p}=0.544, \varphi=0.072): 5(29.4 \%)$ patients were in the 'low', $10(58.8 \%)$ in the 'moderate' and $2(11.8 \%)$ in the 'high' risk category (table 1$)$. The ABCD3-I score reached statistical significance $(\mathrm{p}=0.021$, $\varphi=0.181)$ : 1 patient (5.9\%) was in the 'low' category, 14 (82.4\%) were in the 'moderate' and $2(11.8 \%)$ in the 'high' risk group. The presence of AF (1 of 17 patients; $5.9 \%$ ) was not significantly correlated with early stroke $(\mathrm{p}=$ $0.647, \varphi=-0.03$ ), nor was carotid stenosis $\geq 50 \%$ ( 3 of 17 patients; $17.6 \% ; \mathrm{p}=0.782, \varphi=0.018)$. MR-DWI-positive findings (6 patients; $35.3 \%$ ) also failed to predict early stroke ( $p=0.143, \varphi=0.096)$. Symptom fluctuations at onset showed the best correlation with early stroke: the majority of patients with an early stroke $(13 ; 76.5 \%)$ presented with fluctuating TIA ( $\mathrm{p}<0.001, \varphi=0.297$ ).

The combination of symptom fluctuation and MRDWI-positive findings (4 patients; $23.5 \%$ ) also turned out to show a good association with early stroke with high statistical significance ( $p=0.003, \varphi=0.196)$, while the combination of symptom fluctuations with carotid steno- 
Table 1. Patient characteristics

\begin{tabular}{|c|c|c|c|c|c|}
\hline \multirow[t]{3}{*}{ Parameter } & \multicolumn{4}{|l|}{ Patients } & \multirow[t]{3}{*}{$\mathrm{p}$ value } \\
\hline & \multicolumn{2}{|l|}{ all $(n=235)$} & \multicolumn{2}{|c|}{ with early stroke $(\mathrm{n}=17)$} & \\
\hline & $\mathrm{n}$ & $\%$ & $\mathrm{n}$ & $\%$ & \\
\hline Age, mean $\pm S D$, years & $66.1 \pm 13.9$ & & $70.2 \pm 10.9$ & & \\
\hline Male gender & 130 & 55.3 & 12 & 70.6 & \\
\hline \multicolumn{6}{|l|}{$\mathrm{ABCD} 2$ score } \\
\hline Low risk & 99 & 42.1 & 5 & 29.4 & \\
\hline Moderate risk & 114 & 48.5 & 10 & 58.8 & 0.544 \\
\hline High risk & 22 & 9.4 & 2 & 11.8 & \\
\hline \multicolumn{6}{|l|}{ ABCD3-I score } \\
\hline Low risk & 74 & 31.5 & 1 & 5.9 & \\
\hline Moderate risk & 152 & 64.7 & 14 & 82.3 & 0.021 \\
\hline High risk & 9 & 3.8 & 2 & 11.8 & \\
\hline Atrial fibrillation & 21 & 8.9 & 1 & 5.9 & 0.647 \\
\hline Carotid stenosis $\geq 50 \%$ & 36 & 15.3 & 3 & 17.6 & 0.782 \\
\hline Positive MR-DWI & 50 & 21.3 & 6 & 35.3 & 0.143 \\
\hline Symptom fluctuations & 67 & 28.5 & 13 & 76.5 & $<0.001$ \\
\hline $\begin{array}{l}\text { Fluctuations plus acute infarction } \\
\text { and/or carotid stenosis } \geq 50 \%\end{array}$ & 5 & 2.1 & 4 & 23.5 & 0.029 \\
\hline
\end{tabular}

sis $\geq 50 \%$ did not $(p=0.151 ; \varphi=0.094)$. Similarly, combining fluctuations with carotid stenosis and DWI-positive findings did not improve the result $(\mathrm{p}=0.029, \varphi=$ $0.143)$.

\section{Discussion}

Today, it is a well-known fact that TIAs are not as harmless as originally supposed. In our study, $7.2 \%$ patients suffered an early stroke during hospitalization. This figure is similar to those found in larger population-based studies, which showed an $8 \%$ stroke incidence in the first 7 days after TIA [1] or calculated the stroke risk at $8 \%$ at 30 days in a meta-analysis [4].

To assess the individual risk of early strokes, several parameters/scores have been proposed. The ABCD2 score was first introduced to assess acute stroke risk after TIA for outpatient emergency management $[7,8]$. It has been validated in several studies and found to be of predictive value, as far as general risk associated with risk factors of atherosclerosis is concerned [8, 13-15]. Indeed, most of our patients who suffered an acute stroke after TIA were in the moderate- or high-risk group of the ABCD2 score. However, it did not reach statistical sig- nificance as an individual predictor for an early subsequent stroke after TIAs in our population.

Early positive findings on MR-DWI have shown to be associated with subsequent early stroke $[6,7,16]$. However, although similar to numbers in these larger studies, only 6 of 17 patients with early stroke $(35.3 \%)$ were MRDWI positive in our series, which failed to reach statistical significance. This again mirrors results from previous studies, in which MR-DWI findings were usually combined with risk factors with different degrees of atherosclerosis or scores to reach statistical significance $[6,16]$.

Similarly, carotid stenosis was not correlated with early subsequent stroke in our study if used as a stand-alone parameter. However, we could demonstrate a favorable predictive value of the ABCD3-I score $(p=0.021)$, in which carotid stenosis is included. This means that each of the factors alone (ABCD2 score, brain imaging, carotid stenosis) have weak predictive power if not combined.

Although AF is a recognized risk factor for stroke and requires oral anticoagulation for stroke prevention, it has not been well examined independently as a risk factor for early stroke following TIA. A recent study showed no significant association between AF and risk of early stroke in 343 TIA patients; it was assumed that it was because of the relatively small sample size and the beneficial effect of 
early oral anticoagulation [17]. This may also be the case in our study, where the presence of AF was not significantly correlated with early stroke.

Symptom fluctuations during or directly following TIAs proved to be of considerable value for predicting early stroke risk, provided prospectively repeated examinations are performed. Rates of up to $31 \%$ are described in the literature [12], and we have found similar percentages in a previous (27\%) [11], as well as in our present, study (28.5\%). However, a direct comparison with other scores or associated diagnosis of AF, carotid stenosis, or early stroke signs in MRI has not been systematically addressed in any of these studies. Indeed, in our present study, symptom fluctuation turned out to be the best predictive parameter for early stroke ( $\mathrm{p}<0.001, \varphi=0.297$ ). We defined 'symptom fluctuation' strictly as fluctuations of neurological clinical deficit of cerebrovascular origin during the acute phase of the first $24 \mathrm{~h}$, in contrast to the definition of 'dual TIA' in the ABCD3-I score, which can include TIAs within a time window of 7 days. Combining this parameter with positive DWI and/or carotid stenosis also led to an excellent, statistically significant correlation with early stroke.

Despite some limitations of this study, performed in a single-center design with limited sample size, confirming data now demonstrates the superiority of a single specific parameter versus general risk scores for early stroke risk prediction. Using this simple parameter is not costly, does not require additional, time-consuming technology and identifies individual patients at highest risk who will benefit from continuous stroke unit monitoring to be able to manage thrombolysis within the shortest time limits once subsequent ischemic events occur.

\section{Disclosure Statement}

The authors have nothing to disclose.

\section{References}

1 Daffertshofer M, Mielke O, Pullwitt A, Felsenstein M, Hennerici M: Transient ischemic attacks are more than 'ministrokes'. Stroke 2004;35:2453-2458.

2 Giles MF, Rothwell PM: Risk of stroke early after transient ischaemic attack: a systematic review and meta-analysis. Lancet Neurol 2007;6:1063-1072.

-3 Johnston SC, Gress DR, Browner WS, Sidney $S$ : Short-term prognosis after emergency department diagnosis of TIA. JAMA 2000;284: 2901-2906.

- 4 Wu CM, McLaughlin K, Lorenzetti DL, Hill MD, Manns BJ, Ghali WA: Early risk of stroke after transient ischemic attack: a systematic review and meta-analysis. Arch Intern Med 2007;167:2417-2422.

5 Prabhakaran S, Chong JY, Sacco RL: Impact of abnormal diffusion-weighted imaging results on short-term outcome following transient ischemic attack. Arch Neurol 2007;64: 1105-1109.

6 Purroy F, Montaner J, Rovira A, Delgado P, Quintana M, Alvarez-Sabin J: Higher risk of further vascular events among transient ischemic attack patients with diffusion-weighted imaging acute ischemic lesions. Stroke 2004; 35:2313-2319.

7 Giles MF, Albers GW, Amarenco P, Arsava EM, Asimos AW, Ay H, Calvet D, Coutts SB, Cucchiara BL, Demchuk AM, Johnston SC, Kelly PJ, Kim AS, Labreuche J, Lavallee PC, Mas JL, Merwick A, Olivot JM, Purroy F, Ro- samond WD, Sciolla R, Rothwell PM: Early stroke risk and $\mathrm{ABCD} 2$ score performance in tissue- vs time-defined TIA: a multicenter study. Neurology 2011;77:1222-1228.

8 Johnston SC, Rothwell PM, Nguyen-Huynh MN, Giles MF, Elkins JS, Bernstein AL, Sidney S: Validation and refinement of scores to predict very early stroke risk after transient ischaemic attack. Lancet 2007;369:283-292.

$\checkmark 9$ Giles MF, Albers GW, Amarenco P, Arsava MM, Asimos A, Ay H, Calvet D, Coutts S, Cucchiara BL, Demchuk AM, Johnston SC, Kelly PJ, Kim AS, Labreuche J, Lavallee PC, Mas JL, Merwick A, Olivot JM, Purroy F, Rosamond WD, Sciolla R, Rothwell PM: Addition of brain infarction to the $\mathrm{ABCD} 2$ score (ABCD2I): a collaborative analysis of unpublished data on 4,574 patients. Stroke 2010;41:1907-1913.

10 Merwick A, Albers GW, Amarenco P, Arsava EM, Ay H, Calvet D, Coutts SB, Cucchiara BL, Demchuk AM, Furie KL, Giles MF, Labreuche J, Lavallee PC, Mas JL, Olivot JM, Purroy F, Rothwell PM, Saver JL, Sheehan OC, Stack JP, Walsh C, Kelly PJ: Addition of brain and carotid imaging to the $\mathrm{ABCD}(2)$ score to identify patients at early risk of stroke after transient ischaemic attack: a multicentre observationalstudy.Lancet Neurol 2010;9:1060-1069.

11 Chatzikonstantinou A, Willmann O, Jager T, Szabo K, Hennerici MG: Transient ischemic attack patients with fluctuations are at highest risk for early stroke. Cerebrovasc Dis 2009;27: 594-598.
12 Nakajima M, Hirano T, Naritomi H, Minematsu K: Symptom progression or fluctuation in transient ischemic attack patients predicts subsequent stroke. Cerebrovasc Dis 2010;29: 221-227.

13 Bray JE, Coughlan K, Bladin C: Can the $A B C D$ score be dichotomised to identify high-risk patients with transient ischaemic attack in the emergency department? Emerg Med J 2007;24:92-95.

-14 Cucchiara BL, Messe SR, Taylor RA, Pacelli J, Maus D, Shah Q, Kasner SE: Is the ABCD score useful for risk stratification of patients with acute transient ischemic attack? Stroke 2006;37:1710-1714.

15 Tsivgoulis G, Stamboulis E, Sharma VK, Heliopoulos I, Voumvourakis K, Teoh HL, Patousi A, Andrikopoulou A, Lim EL, Stilou L, Sim TB, Chan BP, Stefanis L, Vadikolias K, Piperidou C: Multicenter external validation of the ABCD2 score in triaging TIA patients. Neurology 2010;74:1351-1357.

16 Coutts SB, Simon JE, Eliasziw M, Sohn CH, Hill MD, Barber PA, Palumbo V, Kennedy J, Roy J, Gagnon A, Scott JN, Buchan AM, Demchuk AM: Triaging transient ischemic attack and minor stroke patients using acute magnetic resonance imaging. Ann Neurol 2005; 57:848-854.

17 Calvet D, Touze E, Oppenheim C, Turc G, Meder JF, Mas JL: DWI lesions and TIA etiology improve the prediction of stroke after TIA. Stroke 2009;40:187-192. 